\title{
Ballistic Limit of Stacked Fabrics Made of Ultra-High-Molecular-Weight Fibers Subjected to Hypervelocity Projectile Impacts
}

\author{
By Masahiro NishidA, ${ }^{1)}$ Ken MizUTANi ${ }^{1)}$ and Masumi HigashidE ${ }^{2)}$ \\ 1) Nagoya Institute of Technology, Nagoya, Japan \\ 2) Aerospace Research and Development Directorate, Japan Aerospace Exploration Agency, Chofu, Japan
}

(Received July 31st, 2015)

\begin{abstract}
We examined the penetration thickness and hole size of ultra-high molecular weight polyethylene fiber fabrics when spherical projectiles made of aluminum alloy 2017-T4 struck the fiber fabrics at impact velocities ranging from 1.5 to 3.8 $\mathrm{km} / \mathrm{s}$. At impact velocities less than $3 \mathrm{~km} / \mathrm{s}$, the penetration thickness increased with impact velocity, whereas the penetration thickness decreased with increasing impact velocity over $3 \mathrm{~km} / \mathrm{s}$. An impact velocity over $3 \mathrm{~km} / \mathrm{s}$ resulted in projectile fragmentation, and the area of the penetration holes changed with penetration thickness of the projectiles. The impact crater was bulb shaped.
\end{abstract}

Key Words: Space Debris, Hypervelocity Impact, Bumper Shield, High-strength Fibers

\section{Introduction}

Space debris often strikes space stations and spacecraft at hypervelocities. The International Space Station (ISS) employs shields to protect itself from space debris, such as the Whipple shield consisting of thin plates, and the stuffed Whipple shield made of multi-layer insulation (MLI) using Nextel ceramic fabrics and Kevlar fabrics. Much research has considered improvements to space debris shields. When space debris perforates a shield, a debris cloud is formed, fragments are ejected from the target surface, and the fragmented projectiles are scattered widely. These ejecta and fragments have the potential to become space debris (known as secondary debris).

Even small space debris striking satellites may trigger mission failure. Therefore, satellite protection against debris impact is necessary, and the Japan Aerospace Exploration Agency (JAXA) has published a handbook on debris protection design of unmanned spacecraft. Components such as expandable structures and wire harnesses cannot be always installed inside the satellite structure and are unsafe for debris impact. Flexible space debris shields are required for components such as expandable structures and wire harnesses. Higashide et al. proposed a fabric bumper shield made of high strength fiber and studied the ballistic limit of fabrics made of aramid fiber, glass fiber covered with polytetrafluoroethylene (PTFE), ceramic fiber ${ }^{1,2)}$ and PBO fiber ${ }^{3)}$. Tamura et al. studied space debris shields made of Nextel fiber and examined penetration holes of hypervelocity impacts and projectile fragmentation ${ }^{4,5)}$. For the purpose of application to a new space suit, Kawase et al. ${ }^{6)}$ studied absorbed energies of fiber fabrics made of polyacrylate, para-amide, nylon, and PBO subjected to hypervelocity impacts.

In this study, spherical projectiles made of aluminum alloy 2017-T4 struck ultra-high molecular weight polyethylene (UHMW-PE) fiber fabrics at hypervelocities, and penetration thickness and penetration hole size were examined. The fiber fabrics were observed after impact experiments. The relationships between the penetration thickness and projectile fragmentation are also discussed.

\section{Experimental Methods}

High-strength fibers such as aramid fiber have been developed and their properties examined in detail. Among the many high-strength fibers available, ultra-high molecular weight polyethylene (UHMW-PE) fibers have received a lot of attention as high-quality protective materials because they have low density and high specific strength. UHMW-PE fiber fabrics are being used for protective body armors as well as aramid fiber fabrics.

In this study, three types of plane woven UHMW-PE fiber fabrics, DD1312, DD1312NH and DD1215, made from Dyneema ${ }^{\circledR}$ SK60 and SK71, Toyobo, were used for impact experiments. The properties of these fiber fabrics ${ }^{7)}$ are shown in Table 1. The fabric densities of DD1312 and DD1312HN are the same, and less than that of DD1215 because the yarn diameter of DD1215 is greater than that of DD1312 and DD1312HN. The properties of the fibers ${ }^{7)}$ are shown in Table 2. The tensile strength and tensile modulus of fiber type SK71 are greater than those of fiber type SK61. In order to examine the effects of fiber type, DD1312 and DD1312 HN were employed for impact experiments.

Fifty sheets of the fabrics with a width of $100 \mathrm{~mm}$ and a length of $155 \mathrm{~mm}$ were stacked on an aluminum alloy plate and clamped by two plates separated by $110 \mathrm{~mm}$ as shown in Fig. 1. The torque of the screw was fixed at $0.6 \mathrm{Nm}$ using a torque wrench. The experimental setup was designed as in a previous study ${ }^{1)}$.

Projectiles with a diameter of $1 \mathrm{~mm}$ (mass $1.5 \mathrm{mg}$ ) and made of aluminum alloy (2017-T4) were used based on the international standard ISO11227 ${ }^{8}$. A two-stage light-gas gun 
of Nagoya Institute of Technology was used to accelerate the projectiles with a sabot. Three projectiles were put into a sabot and some of three struck the target simultaneously. The impact velocities were 1.5 to $3.8 \mathrm{~km} / \mathrm{s}$.

Table 1. Properties of fabrics made from Dyneema ${ }^{\circledR}$.

\begin{tabular}{|l|c|c|c|}
\hline & DD1312 & DD1312HN & DD1215 \\
\hline Areal density, g/cm ${ }^{2}$ & 174 & 170 & 166 \\
\hline Thickness, mm & 0.36 & 0.36 & 0.49 \\
\hline Fabric density, yarns/in & $45 \times 47$ & $45 \times 47$ & $15 \times 15$ \\
\hline Fineness, dtex & 440 & 440 & 1320 \\
\hline Fiber type & SK60 & SK71 & SK60 \\
\hline
\end{tabular}

Table 2. Properties of Dyneema ${ }^{\circledR}$, SK60 and SK71.

\begin{tabular}{|l|c|c|}
\hline & SK60 & SK71 \\
\hline Density, g/cm & 3.97 & 0.97 \\
\hline Tensile strength, GPa & 2.6 & 3.5 \\
\hline Tensile modulus, GPa & 79 & 123 \\
\hline Elongation at break, \% & $3-5$ & $3-5$ \\
\hline
\end{tabular}

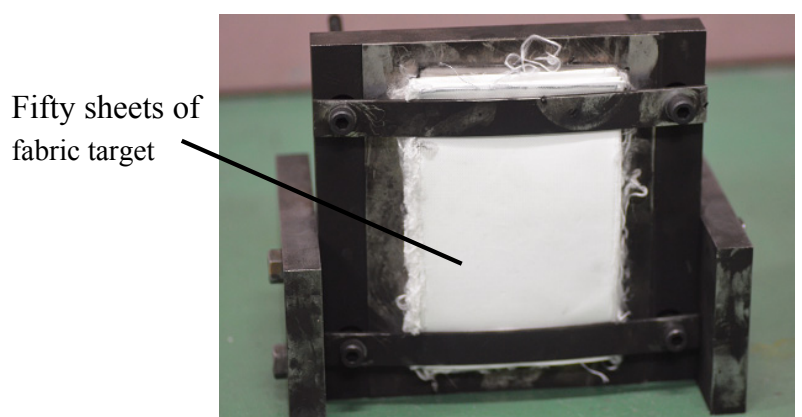

Fig. 1. Experimental setup showing the clamped fabric target before impact.

\section{Results and Discussion}

\subsection{Observation of target after impact}

Figure 2 shows photographs of DD1312 after impact experiments at an impact velocity of $3.5 \mathrm{~km} / \mathrm{s}$. Figure 2(a) shows the clamped fabric target blackened by soot after the impact experiments. Figures 2(b)-(f) show images of projectile penetration holes for the different layers. The penetration holes of the fourth layer and the sixth layer are larger than that of the first layer. In the eighth layer, as shown in Fig. 2(e), we can see several fragments of the projectile, and in the twelfth layer, we can see some fragments of the projectile and a small penetration hole. No penetration hole can be seen in the photograph of the thirteenth layer (Fig. $2(\mathrm{~g}))$. In this case, we determined that the penetration thickness is $4.32 \mathrm{~mm}$, which is twelve times the fabric thickness of $0.36 \mathrm{~mm}$.

\subsection{Penetration thickness}

Figure 3 shows the effects of impact velocity on penetration thickness. When the impact velocities were 1.7 and $2.7 \mathrm{~km} / \mathrm{s}$, the projectiles were slightly fragmented, and the projectile weights after the impact experiments were only slightly smaller than that before the impact experiments $(1.5 \mathrm{mg})$. The projectiles were deformed slightly, as shown in Figs. 4(a) and (b). In such impacts, the penetration thickness increased with impact velocity. When the impact velocity was further increased, it resulted in the fragmentation of the projectiles, and the fragments recovered from the fabric targets were very small. At impact velocities of over $3 \mathrm{~km} / \mathrm{s}$, the penetration thickness decreased with increasing impact velocity. Table 3 shows the maximum mass of the fragments. The projectile fragmentation clearly affected the penetration thickness. The projectile was severely deformed when the impact velocity was $3.76 \mathrm{~km} / \mathrm{s}$, as shown in Figs. 4(c).

\subsection{Area of penetration holes}

The areas of the penetration holes were measured from the photographs of the fabrics using the image analysis software ImageJ. Figure 5 shows the areas of the penetration holes for each layer of DD1312. In Fig. 5(a), the area of the hole in the first layer (entrance of penetration crater) is almost the same as that of the internal layers. For the sixth layer or its rear layer, the area of the hole decreased with increasing penetration thickness. Figures 5(b)-(e) show that the area of the hole in the first layer (entrance of penetration crater) was smaller than that of the internal layers.

The penetration crater was bulb shaped when the impact velocity was over $2.75 \mathrm{~km} / \mathrm{s}$. When the impact velocity increased, this shape became more obvious. This shape is similar to that of impact craters in stacked porous aluminum plates ${ }^{9}$. The size of the penetration crater increased with impact velocity. When the impact velocity was over $3.0 \mathrm{~km} / \mathrm{s}$, it resulted in projectile fragmentation. The size of the penetration crater at $3.50 \mathrm{~km} / \mathrm{s}$ was the maximum in the case of DD1312. It is highly likely that projectile fragmentation results in the large size of the holes.



(a) Clamped fabric target after the impact test.

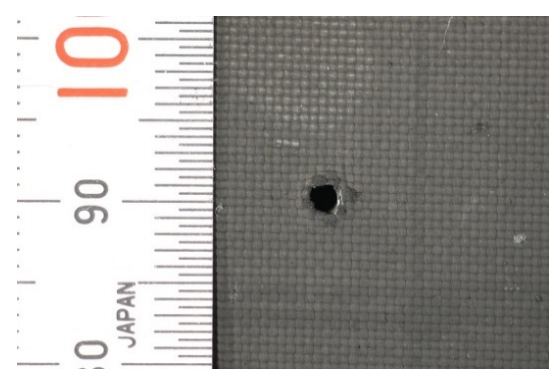

(b) First layer 


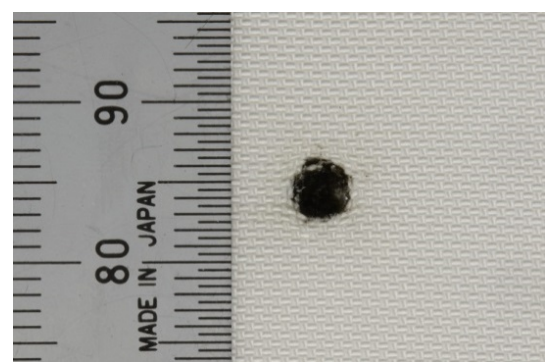

(c) Fourth layer

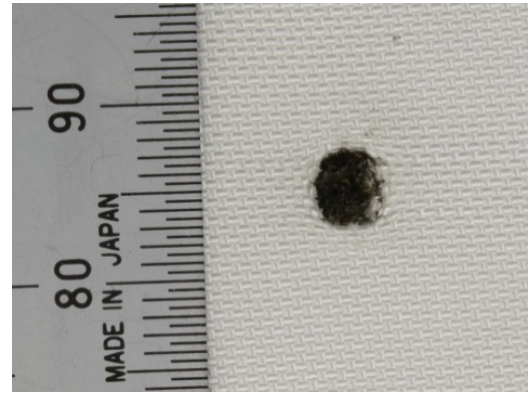

(d) Sixth layer

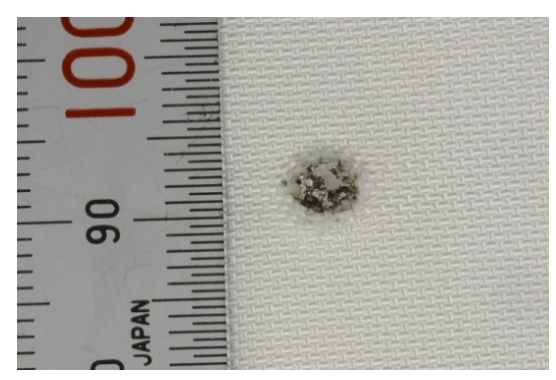

(e) Eighth layer (Photograph taken from back side)

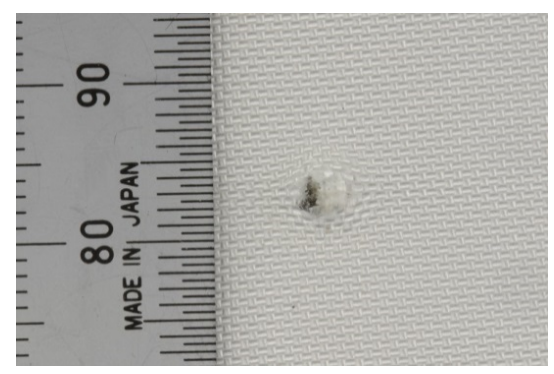

(f) Twelfth layer

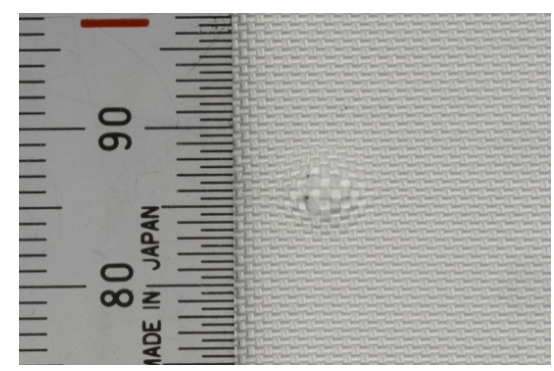

(g) Thirteenth layer (Non-perforation)

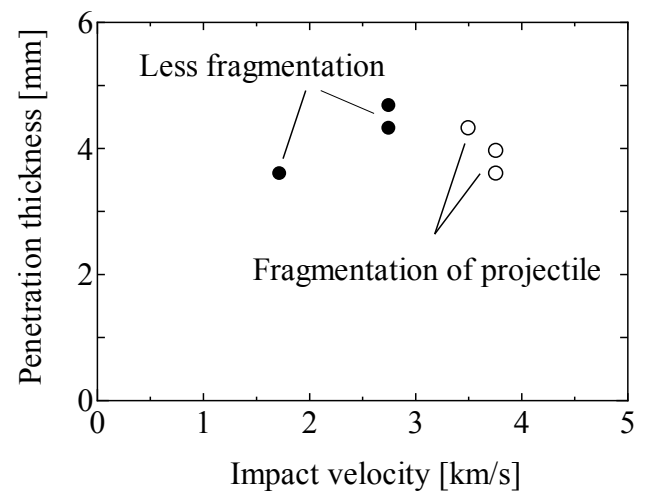

Fig. 3. Effects of impact velocity on penetration thickness.

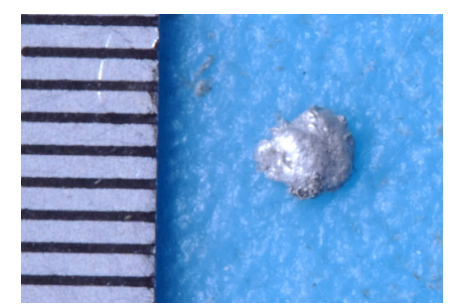

(a) $1.1 \mathrm{mg}$, impact velocity $1.72 \mathrm{~km} / \mathrm{s}$

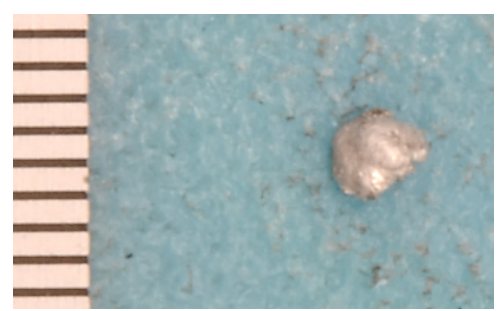

(b) $1.2 \mathrm{mg}$, impact velocity $2.75 \mathrm{~km} / \mathrm{s}$

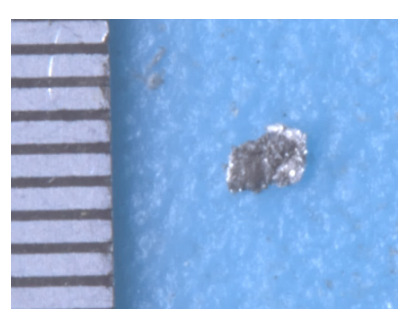

(c) $0.4 \mathrm{mg}$, impact velocity $3.76 \mathrm{~km} / \mathrm{s}$

Fig. 4. Photographs of fragments recovered from DD1312 fabric targets.

Table 3. Maximum mass of fragments in DD1312.

\begin{tabular}{ccc}
\hline $\begin{array}{c}\text { Impact velocity, } \\
\mathrm{km} / \mathrm{s}\end{array}$ & $\begin{array}{c}\text { Penetration thickness, } \\
\mathrm{mm}\end{array}$ & $\begin{array}{c}\text { Maximum fragment } \\
\text { mass after tests, } \mathrm{mg}\end{array}$ \\
\hline 1.72 & 3.60 & 1.1 \\
\hline \multirow{2}{*}{2.75} & 4.32 & 1.2 \\
& 4.68 & 1.4 \\
\hline 3.50 & 4.32 & 0.7 \\
\hline \multirow{2}{*}{3.76} & 3.60 & 0.4 \\
& 3.96 & 0.5 \\
\hline
\end{tabular}

Fig. 2. Photographs of DD1312 fabrics after impact experiments at an impact velocity of $3.5 \mathrm{~km} / \mathrm{s}$. 


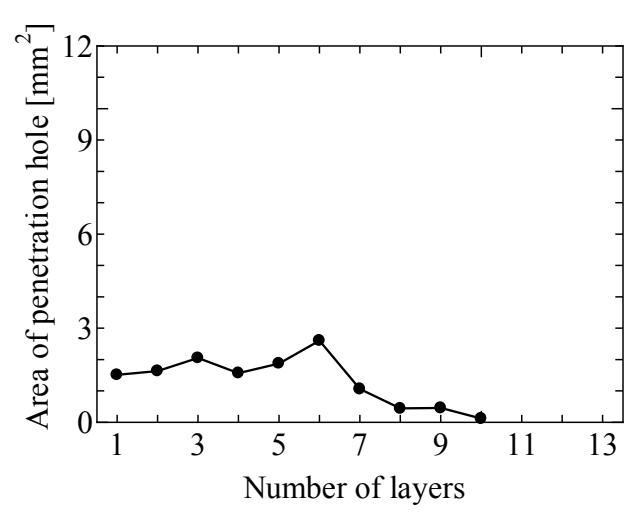

(a) Impact velocity $1.72 \mathrm{~km} / \mathrm{s}$

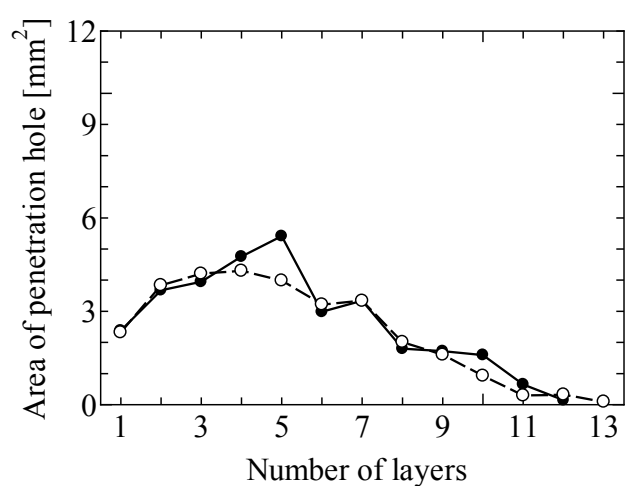

(b) Impact velocity $2.75 \mathrm{~km} / \mathrm{s}$

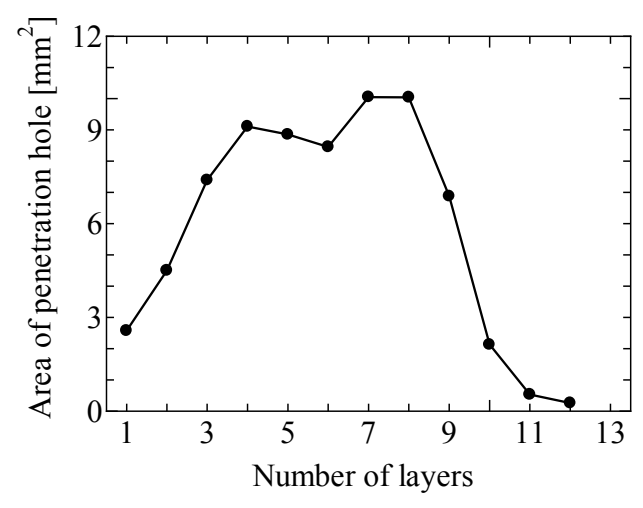

(c) Impact velocity $3.50 \mathrm{~km} / \mathrm{s}$

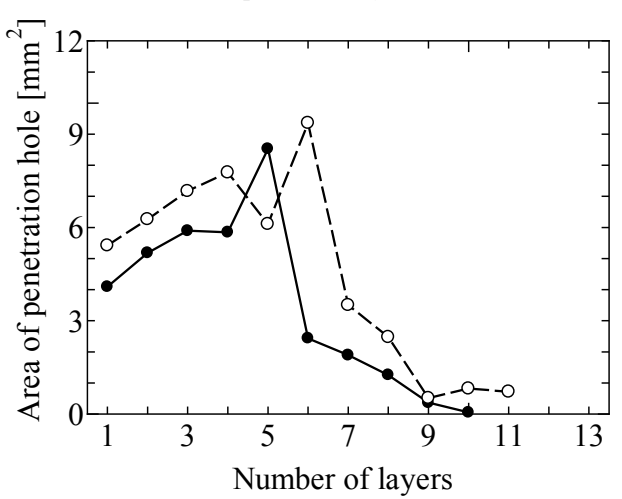

(d) Impact velocity $3.76 \mathrm{~km} / \mathrm{s}$

Fig. 5. Crater shape of DD1312

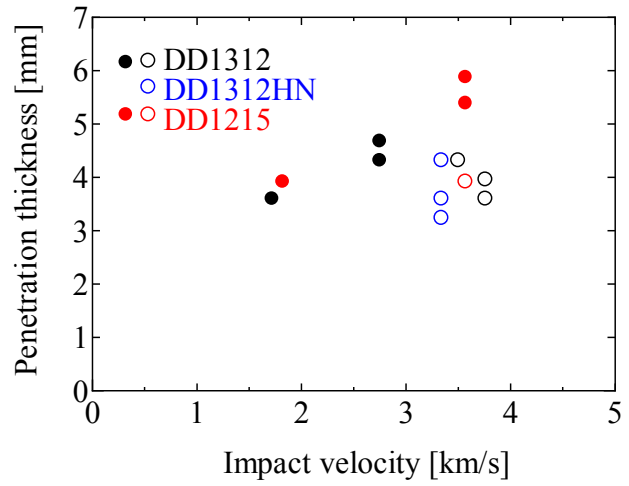

Fig. 6. Effects of impact velocity on the penetration thickness of three types of fiber fabrics. Open circles indicate experiments with severe projectile fragmentation, solid circles indicate those without severe projectile fragmentation

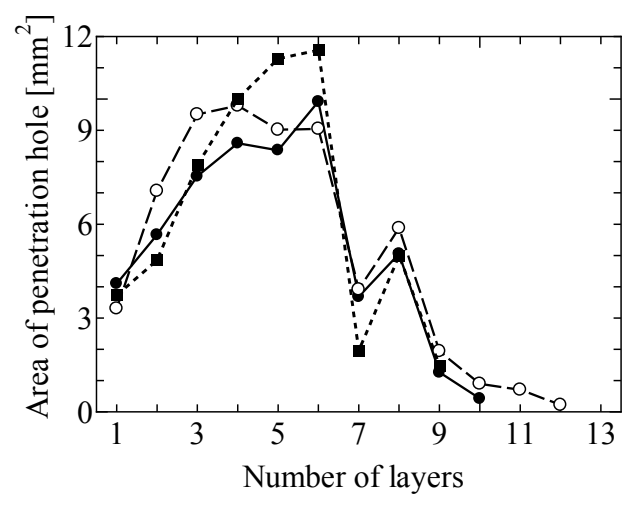

(a) DD1312NH, $3.34 \mathrm{~km} / \mathrm{s}$, open circle: penetration thickness $4.32 \mathrm{~mm}$, solid circle: penetration thickness $3.60 \mathrm{~mm}$, solid squire: $3.24 \mathrm{~mm}$

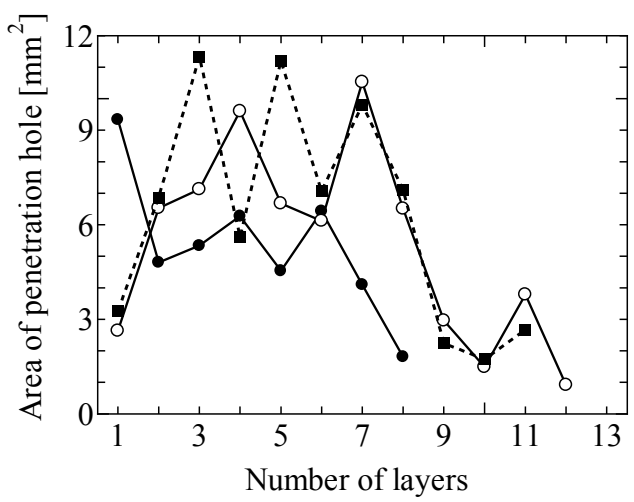

(b) DD1215, $3.57 \mathrm{~km} / \mathrm{s}$, open circle: penetration thickness $5.88 \mathrm{~mm}$, solid circle: penetration thickness $3.92 \mathrm{~mm}$, solid squire: $5.39 \mathrm{~mm}$

Fig. 7. Crater shape of DD1312NH and DD1215.

Table 4. Effects of fabric type on maximum fragment mass at impact velocities over $3 \mathrm{~km} / \mathrm{s}$

\begin{tabular}{cccc}
\hline \multirow{2}{*}{ Fabric type } & $\begin{array}{c}\text { Impact } \\
\text { velocity, } \\
\mathrm{km} / \mathrm{s}\end{array}$ & $\begin{array}{c}\text { Penetration } \\
\text { thickness, } \\
\mathrm{mm}\end{array}$ & $\begin{array}{c}\text { Maximum } \\
\text { fragment mass } \\
\text { after tests, mg }\end{array}$ \\
\hline \multirow{2}{*}{$\mathrm{DD} 1312$} & 3.76 & 3.60 & 0.4 \\
& 3.50 & 3.96 & 0.5 \\
\hline \multirow{2}{*}{$\mathrm{DD} 1312 \mathrm{HN}$} & 3.34 & 4.32 & 0.7 \\
\hline \multirow{2}{*}{$\mathrm{DD} 1215$} & \multirow{2}{*}{3.57} & 3.60 & 0.4 \\
\cline { 2 - 4 } & & 4.32 & 0.7 \\
\hline
\end{tabular}




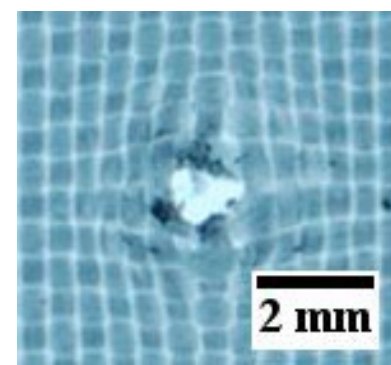

(a) $\mathrm{DD} 1312,3.76 \mathrm{~km} / \mathrm{s}$

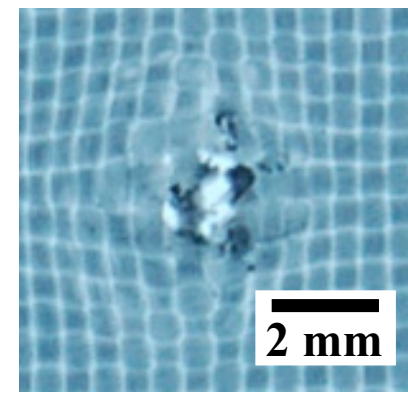

(b) $\mathrm{DD} 1312 \mathrm{HN}, 3.34 \mathrm{~km} / \mathrm{s}$

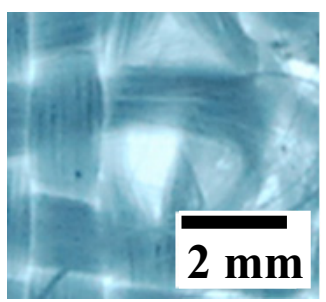

(c) $\mathrm{DD} 1215,3.57 \mathrm{~km} / \mathrm{s}$

Fig. 8. Photographs of the penetration hole for the tenth layer.

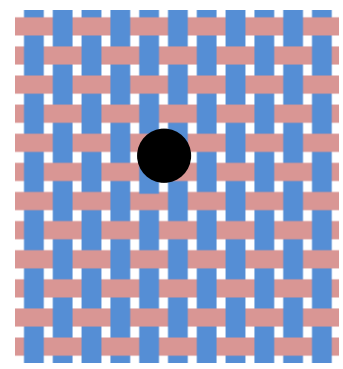

(a) DD1312 and DD1312HN

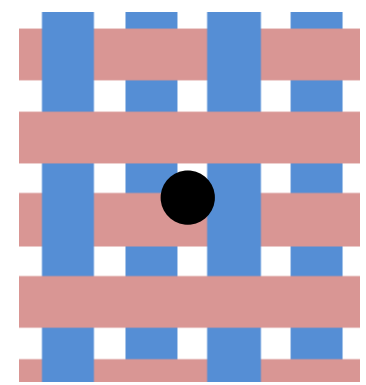

(b) DD1215

Fig. 9. Comparison between yarn diameter and projectile diameter. Black circle shows the size of the projectiles.

\subsection{Effects of fabric type}

Figure 6 shows the effects of fabric type and fiber type on penetration thickness. Open circles show the results of experiments in which there was severe projectile fragmentation and only small fragments of the projectile were recovered. Solid circles show the results of experiments without severe projectile fragmentation. The results from fabric types DD1312 (fiber type SK60), black circles, and DD1312HN (fiber type SK70), blue circles, show that the fiber type did not affect the penetration thickness. The fabric type DD1215 has a low fabric density, and its penetration thickness, red circles, varied over a wide range.

Figure 7 shows the areas of the penetration holes for each layer of DD1312HN and DD1215. Compared to DD1312 in Fig. 5(c), the crater of DD1312HN shows a clear bulb shape, which indicates that the area of the hole in the first layer is smaller than that of the internal layers. In contrast, the crater shape of DD1215 did not show such obvious trends. Table 4 shows the maximum mass of the fragments at impact velocities of over $3 \mathrm{~km} / \mathrm{s}$. When the penetration thickness was large, the maximum fragment was also large. Around an impact velocity of $3.5 \mathrm{~km} / \mathrm{s}$ in Fig. 6, we could not collect any large fragments because projectile fragmentation was severe. This occurred in one of three results for both DD1312NH and DD1215.

In order to clarify the reason for the large variation in penetration thicknesses in Fig. 6 and the unclear crater shape of DD1215 in Fig. 7(b), penetration holes after impact tests were observed in detail and the yarn diameter was compared to the projectile diameter. Figures 8(a) and (b) show that in the case of DD1312 and DD1312NH, the projectile seemed to strike several yarns. On the other hand, in the case of DD1215, the projectile seemed to strike only a few yarns because of the low fabric density. We calculated the number of yarns struck by the projectiles. In the case of DD1312 and DD1312HN, the number was determined to be 3.6 assuming a fabric density of $45 \times 47$ yarns/in in the following equations. The number of yarns struck in DD1215 was determined to be 1.2 .

For DD1312 and DD1312HN: For DD1215:

$$
1.0 \times 10^{-3} \times(45+47) \times(1000 / 25.4)=3.62 \text { yarns }
$$

$$
1.0 \times 10^{-3} \times 2 \times 15 \times(1000 / 25.4)=1.18 \text { yarns }
$$

Figure 9 shows a schematic view of the projectile impact area. The black circle shows the size of projectile. The number of yarns struck by projectiles for DD1312 and DD1312HN was greater than that for DD1215. When the number of yarns was greater, the penetration thickness and crater shape were stabilized. Low fabric density is thought to be the cause of the large variation in penetration behavior. For low density fabrics, the projectile was sometimes severely fragmented and sometimes had very little fragmentation.

\section{Conclusion}

At impact velocities less than $3 \mathrm{~km} / \mathrm{s}$, the penetration thickness increased with impact velocity, whereas the 
penetration thickness decreased with increasing impact velocity when the impact velocity was over $3 \mathrm{~km} / \mathrm{s}$. When the impact velocity was over $3 \mathrm{~km} / \mathrm{s}$, it resulted in projectile fragmentation. The crater of fabric types DD1312 and DD1312HN was bulb shaped. The fabric density affected the stability of penetration thickness and the crater shape.

\section{Acknowledgments}

The authors are greatly indebted to Dr. Koichi Hayashi of National Institute of Technology, Toba College and Dr. Takamasa Kikuchi of Nihon University for their valuable advice with respect to sabot separation technique. The authors are greatly indebted to Toyobo Co., Mr. Yukihiro Nomura and Mr. Akira Hamano, for their help with Dyneema fabric specimens.

\section{References}

1) Higashide, M., Onose, N. and Hasegawa, S.: Ballistic Limit Thickness and Weight of High Strength Fiber Fabrics for Sub-millimeter Steel Sphere Impact at $6 \mathrm{~km} / \mathrm{s}$, Transaction of JSASS, Aerospace Tech. Japan, 12 (2014), Pr_1-Pr_5.
2) Higashide, M., Onose, N. and Hasegawa, S.: Ballistic Limit Weight and Thickness of Kevlar and Beta Cloth for Sub-millimeter Debris Impact, JAXA Special Publication: Proc. 5th Space Debris Workshop, (2014), pp. 202-212.

3) Higashide, M., Onose, N. and Hasegawa, S.: Ballistic Limit of Aramid Fiber Fabrics, Proceedings of Space Plasma Workshop, (2014), paper \#3 (in Japanese).

4) Onoe, S., Sutipanya, P., Saito, F., Tamura, H.: Impact Damage of Spherical Aluminum Projectiles by Hypervelocity Impact on Single-Ply High-Strength Ceramic Fabrics, Proc. Sym. Shock Waves in Japan, (2009), pp. 55-56 (in Japanese).

5) Sutipanya, P., Saito, F., Tamura, H.: Hypervelocity Impact of Spherical Aluminum Projectiles on Nextel-yarns, Proc. Sym. Shock Waves in Japan, (2010), pp. 209-210 (in Japanese).

6) Kawase, S., Aoki, I., Sato, T., Wada, Y.: Yamaguchi, T.: Hypervelocity Impact of High Strength Fiber Woven Fabrics, Proc. 57th Space Sciences and Technology Conference, (2013), 2E17 (in Japanese).

7) Toyobo technical data.

8) ISO 11227: Space systems - Test procedure to evaluate spacecraft material ejecta upon hypervelocity impact.

9) Onose, N., Higashide, M., Hasegawa, S.: Hypervelocity Impacts on Porous Metal : As a Capable Candidate for Debris Bumper Shield Material, Transactions of the Japan Society for Aeronautical and Space Sciences, Aerospace Technology Japan, 10, ists28 (2012), pp. Tr_29-Tr_32. 